\title{
A Longitudinal Underserved Community Curriculum for Family Medicine Residents
}

Christine Jacobs, MD; Adam Seehaver, MSW; Sarah Skiold-Hanlin, MS

BACKGROUND AND OBJECTIVES: Postgraduate education in cultural competence and community health is a key strategy for eliminating health disparities in underserved populations. Evidence suggests that an experiential, rather than knowledge-based approach equips physicians with practical and effective communication tools that generalize to a greater diversity of patients and cultures. However, there is limited data about the efficacy of a longitudinal, experiential residency curriculum. This study details the results of a longitudinal underserved community curriculum for family medicine residents training in a federally qualified health center.

METHODS: All residents in the first 5 years of a new residency participated in a longitudinal curriculum of workshops and seminars focused on social determinants of health and cultural competency for underserved patients. Preand postcurriculum surveys assessed knowledge gain. Self-reported Likert scale ratings assessed attitudes and confidence related to underserved care.

RESULTS: Pre/post learning evaluations after each seminar documented average knowledge increase of $31.0 \%$ and $28.8 \%$, respectively. At the end of the 3-year curriculum, $\mathbf{8 1 . 8 \%}$ of residents reported confidence in their ability to incorporate culturally relevant information into a treatment plan and $57.1 \%$ of residents reported feeling very aware of obstacles faced by underserved populations seeking health care and of the relationship between sociocultural background, health, and medicine.

CONCLUSIONS: A longitudinal, experiential curriculum in underserved community health and cultural competence can improve resident knowledge and attitudes with respect to health disparities and delivering health care to diverse patient populations.

(Fam Med. 2019;51(1):48-54.)

doi: 10.22454/FamMed.2019.320104

ultural competence is a key strategy for addressing growing health disparities..$^{1-6}$ Postgraduate (PG) medical cultural competence education has traditionally been a knowledge-based approach to diverse cultural beliefs, values, and behaviors. ${ }^{2}$ However, didactic approaches may fail to skills-based approach can equip physicians with tools that are effective across diverse populations. ${ }^{1,3}$

Although the relationship between provider cultural competence and clinical outcomes needs further study, research suggests that lack of attention to cultural issues can negatively impact patient satisfaction and treatment adherence. ${ }^{5}$ Educators recommend multifaceted cultural competence education taught throughout the duration of medical education. ${ }^{7,8}$ However, there is limited data on longitudinal residency curriculum to increase the cultural competence of physicians in an urban underserved area.

This study describes the design, implementation, and evaluation of a longitudinal underserved community curriculum (LUCC) implemented during the first 5 years of an urban underserved family medicine residency.

\section{Methods \\ Curriculum}

From July 2011-June 2016, all residents $(\mathrm{N}=22)$ in a new Saint Louis University Family Medicine Residency in St Louis, Missouri participated in aspects of the LUCC (Table 1). Three cohorts of residents $(\mathrm{N}=11$; $57.1 \%$ female) completed the entire 3-year curriculum including 12

From the Department of Family and Community Medicine, Saint Louis University School of Medicine, St Louis, MO. 
Table 1: Number of Resident Participants in LUCC During Study Period 2011-2016

\begin{tabular}{|c|c|c|c|}
\hline Resident Cohort & $\begin{array}{c}\text { PGY1 } \\
\text { (Seminars Only) }\end{array}$ & $\begin{array}{c}\text { PGY2 } \\
\text { (Seminars+Workshops) }\end{array}$ & $\begin{array}{c}\text { PGY3 } \\
\text { (Seminars Only) }\end{array}$ \\
\hline 1 & 4 residents & 3 residents & 3 residents \\
\hline 2 & 4 residents & 4 residents & 4 residents \\
\hline 3 & 4 residents & 4 residents & 4 residents \\
\hline 4 & 4 residents & 3 residents* & \\
\hline 5 & 6 residents & & \\
\hline
\end{tabular}

* Only seminar data used.

Table 2: Longitudinal Underserved Community Curriculum Workshops

\begin{tabular}{|c|c|c|c|c|c|c|}
\hline Workshop Title & Activities & $\mathbf{n}^{\mathrm{a}}$ & Pre & Post & Change $^{b}$ & $P$ Value \\
\hline $\begin{array}{l}\text { Addiction and } \\
\text { Homelessness }\end{array}$ & Learning session, community agency visits & 13 & $42.6 \%$ & $84.6 \%$ & $42.0 \%$ & $<.0001$ \\
\hline $\begin{array}{l}\text { Child Abuse and } \\
\text { Family Dynamics }\end{array}$ & $\begin{array}{l}\text { Emergency dept social worker as guest speaker, case } \\
\text { studies, conversation with patient with abuse history. }\end{array}$ & 10 & $45.5 \%$ & $79.1 \%$ & $33.6 \%$ & $<.0001$ \\
\hline $\begin{array}{l}\text { Child Development } \\
\text { and Education }\end{array}$ & $\begin{array}{l}\text { Simulation of learning disabilities, parent panels } \\
\text { about experience with children with learning } \\
\text { disabilities. }\end{array}$ & 12 & $53.3 \%$ & $67.5 \%$ & $14.2 \%$ & .143 \\
\hline Pediatric Nutrition & $\begin{array}{l}\text { Task buying healthy lunch for } \$ 5 \text { within walking } \\
\text { distance of } \mathrm{CHC}^{\mathrm{d}} \text {, exploration of walking/ green space } \\
\text { for safe physical activity for patients. }\end{array}$ & 8 & $55.4 \%$ & $74.4 \%$ & $19.0 \%$ & .014 \\
\hline Senior Safety Net & $\begin{array}{l}\text { Visit senior housing, senior day care and speech and } \\
\text { hearing agency. }\end{array}$ & 6 & $36.4 \%$ & $68.2 \%$ & $31.8 \%$ & .008 \\
\hline $\begin{array}{l}\text { Chronic Disease } \\
\text { Management: } \\
\text { Diabetes }\end{array}$ & $\begin{array}{l}\text { Diabetes guideline review, conversation with affected } \\
\text { patients. }\end{array}$ & 9 & $35.2 \%$ & $88.9 \%$ & $53.7 \%$ & $<.0001$ \\
\hline $\begin{array}{l}\text { Chronic Disease } \\
\text { Management: COPD }\end{array}$ & $\begin{array}{l}\text { COPD guideline review, conversation with affected } \\
\text { patients. }\end{array}$ & 9 & $74.6 \%$ & $73.0 \%$ & $-1.6 \%$ & .838 \\
\hline $\begin{array}{l}\text { Addiction and } \\
\text { Homelessness }\end{array}$ & $\begin{array}{l}\text { Visit community mental health and social service } \\
\text { agency, shadow case workers of clients with insecure } \\
\text { housing. }\end{array}$ & 13 & $42.6 \%$ & $84.6 \%$ & $42.1 \%$ & $<.0001$ \\
\hline Medical Humanism & $\begin{array}{l}\text { Readings, videos and discussion of the practice of } \\
\text { medicine and medical mistakes. }\end{array}$ & 9 & $11.1 \%$ & $83.3 \%$ & $72.2 \%$ & $<.0001$ \\
\hline $\begin{array}{l}\text { Neighborhood } \\
\text { HealthCare Safety } \\
\text { Net }\end{array}$ & $\begin{array}{l}\text { Visit neighboring } \mathrm{CHC} \text { with resources and } \\
\text { community health programs. }\end{array}$ & 9 & $23.9 \%$ & $30.6 \%$ & $6.7 \%$ & .552 \\
\hline $\begin{array}{l}\text { Disabilities and } \\
\text { Implicit Bias }\end{array}$ & $\begin{array}{l}\text { Visit disability advocacy and support organization, } \\
\text { "Implicit Bias" test through Harvard University. }\end{array}$ & 6 & $33.3 \%$ & $56.7 \%$ & $23.3 \%$ & .143 \\
\hline International Health & $\begin{array}{l}\text { Education about citizenship and naturalization. } \\
\text { Conversations with three different immigrant } \\
\text { families. }\end{array}$ & 7 & $32.9 \%$ & $78.6 \%$ & $45.7 \%$ & $<.0001$ \\
\hline Overall average & & 98 & $41.2 \%$ & $72.2 \%$ & $31.0 \%$ & $<.0001$ \\
\hline
\end{tabular}

${ }^{a}$ Variations in overall $\mathrm{n}$ size due to some workshops being offered in more years than others. If present (“p”), $\mathrm{n} / \mathrm{n}=$ pre/post sample sizes.

${ }^{b}$ Knowledge change represents the difference in the percentage of questions answered correctly from pretests to posttests for each workshop.

${ }^{\mathrm{c}}$ Pre- and post- are unmatched. Independent samples $t$-test for difference in pre- and posttest knowledge scores.

${ }^{d}$ Community health center

${ }^{\mathrm{e}}$ Chronic obstructive pulmonary disease 
monthly day-long community health workshops during PGY2 focused on health disparities and cultural competencies in urban underserved care. Cohorts four and five completed 2 and 1 year of curriculum, respectively, during the study period.

Monthly day-long experiential workshops for PGY-2 residents were mentored by faculty practicing in underserved care and designed to maximize resident engagement. Workshops included conversations with patients, visits to community organizations, introduction to resources, hands-on clinical workshops, fieldwork, short didactic sessions, and awareness raising exercises. For example, in the addiction and homelessness workshop, residents accompanied outreach professionals into the field to immunize and discuss health related topics with patients.

Monthly community-focused 1-hour seminars for all residents were led by guest speakers from ethnic communities or community agencies and addressed cross-cultural health, health disparities, behavioral health, violence, and health policy.

All residents practiced in a diverse urban federally qualified health center (FQHC) with patients served in a language other than English (15\%) and patients below the poverty level $(55 \%)$.

\section{Evaluation}

Written pre- and posttests at each workshop or seminar evaluated knowledge gain and included written feedback. After each block of 12 PGY-2 workshops, a staff researcher conducted a focus group that was transcribed for feedback and quality improvement. An electronic annual resident survey measured resident confidence and attitudes at the start of PGY1 and late in PGY3. This survey was informed by a systematic review of self-administered measures of cultural competence of health professionals and includes items from the Modified Cultural Competency Self-Assessment Questionnaire, ${ }^{9}$ the Transcultural Self-Efficacy Tool, ${ }^{10,11}$ the Cultural Assessment Survey, ${ }^{12}$ and the Socio-cultural Attitudes in Medicine Inventory. ${ }^{13}$ All surveys were anonymous, thus pre- and posttests were not matched.

\section{Data Analysis}

Pre/post intervention comparative design evaluated knowledge, confidence, and attitudes. The PGY-1 baseline annual resident survey binary confidence and attitude scores were compared to PGY-3 scores using Fisher exact tests. Change in knowledge scores for pre- and posttests for workshops and seminars (Tables 2 and 3) were assessed using independent samples $t$-tests. Preand posttests were not matched, hence, paired sample analysis could not be conducted. All analyses were conducted using SAS v9.4 (SAS Institute, Cary, NC). Qualitative responses were independently analyzed for themes by the first two authors.

The Saint Louis University Institutional Review Board determined evaluation of the curriculum and resident learning to be an exempt study.

\section{Results}

\section{Learner Outcomes}

Resident knowledge after the PGY2 day-long workshops (Table 2) increased $31.0 \%(P<0.0001)$. Average resident knowledge after the seminars with pre- and posttests (Table $3)$ increased $28.8 \%(P<0.0001)$.

On the annual resident survey (Table 4), residents indicated greater awareness of cultural diversity and confidence in caring for people of diverse cultures from PGY1 to PGY3. Resident self-ratings of "good" or "extremely aware" of obstacles faced by groups of color seeking health care increased from $40.0 \%$ to $90.9 \%(P=.024)$, and of "good" or "extremely knowledgeable" of ways cultural factors may influence nursing care increased from $10.0 \%$ to $90.9 \%(P=.0003)$. The proportion of residents indicating "totally confident" or "confident" in incorporating culturally relevant information into a treatment plan significantly increased from $30.0 \%$ to $81.8 \%$ $(P=.030)$. Resident responses regarding beliefs about the influence of socioeconomic and cultural factors on experiences with health care did not reach significance.

\section{Curriculum Feedback}

Two themes emerged from the authors' review of resident written feedback after each workshop (representative comments in Table 5): greater understanding of the challenges and barriers faced by underserved patients, and increased knowledge of community resources.

Resident feedback in the workshop focus groups was used for faculty development and continuous curriculum quality improvement. Focus group feedback occasionally resulted in a minor workshop modification, and hospice was replaced with a disability workshop after one year. Residents frequently noted the value of immersion, as in comments such as "putting ourselves submerged into their situation... especially for the addiction and homelessness one, that was pretty like an eye-opener one for me."

\section{Discussion}

We implemented and evaluated a novel longitudinal curriculum to increase knowledge, awareness, and confidence in diverse underserved health care for residents practicing in an urban FQHC. A review of graduate medical education found few programs with structured block or longitudinal health disparities curricula, and a lack of consensus regarding content. ${ }^{14}$ In many residencies, the principles of underserved care are integrated into training and practice in a way that is not easily extracted. ${ }^{15}$ Our program is unique in its intentionality and longitudinal format that regularly reminded residents of the social determinants of health, provided meaningful experiences with faculty mentors in underserved care and complemented clinical experience with deepening understanding of a diverse population. 
Table 3: Knowledge Change After Seminars ${ }^{a}$

\begin{tabular}{|c|c|c|c|c|c|}
\hline Topic & $\mathbf{n}^{\mathbf{b}}$ & Pre & Post & Change $^{c}$ & $P$ Value \\
\hline Citizenship and naturalization & 17 & $26.1 \%$ & $84.3 \%$ & $58.2 \%$ & $<.0001$ \\
\hline LGBT health & $6 / 5$ & $63.9 \%$ & $93.3 \%$ & $29.4 \%$ & .013 \\
\hline Hispanic culture and health beliefs & 17 & $58.8 \%$ & $78.4 \%$ & $19.6 \%$ & .071 \\
\hline Health care policy legislation in Missouri & 25 & $47.5 \%$ & $91.5 \%$ & $44.0 \%$ & $<.0001$ \\
\hline Cultural competence: somalis & 15 & $62.8 \%$ & $91.4 \%$ & $28.6 \%$ & .002 \\
\hline Universal screening: child mental health & 7 & $48.1 \%$ & $71.4 \%$ & $23.3 \%$ & .167 \\
\hline ADHD-pharmacology & 16 & $39.1 \%$ & $69.4 \%$ & $30.3 \%$ & $<.0001$ \\
\hline Framework for understanding poverty & $12 / 13$ & $61.4 \%$ & $65.3 \%$ & $3.9 \%$ & .680 \\
\hline Affordable care act & 8 & $65.6 \%$ & $93.7 \%$ & $28.1 \%$ & .016 \\
\hline Intimate partner violence & 8 & $51.8 \%$ & $89.3 \%$ & $37.5 \%$ & $<.0001$ \\
\hline Human trafficking & 9 & $87.8 \%$ & $91.1 \%$ & $3.3 \%$ & .716 \\
\hline Navigating cultural differences & 8 & $39.3 \%$ & $67.9 \%$ & $28.6 \%$ & .015 \\
\hline Albania/Kosovo health & $9 / 12$ & $59.3 \%$ & $72.2 \%$ & $13.0 \%$ & .221 \\
\hline Bosnians with war trauma & $10 / 9$ & $50.0 \%$ & $80.6 \%$ & $30.6 \%$ & .002 \\
\hline $\begin{array}{l}\text { Adolescent risky behavior/positive youth } \\
\text { development }\end{array}$ & $6 / 8$ & $50.0 \%$ & $75.0 \%$ & $25.0 \%$ & .033 \\
\hline Minority men's health & 9 & $33.3 \%$ & $36.1 \%$ & $2.8 \%$ & .710 \\
\hline Alzheimer's disease & 7 & $34.3 \%$ & $74.3 \%$ & $40.0 \%$ & .006 \\
\hline Development disabilities & 7 & $26.2 \%$ & $54.8 \%$ & $28.6 \%$ & .001 \\
\hline Art of advocacy & 10 & $30.0 \%$ & $65.0 \%$ & $35.0 \%$ & $<.0001$ \\
\hline Agenda setting & 10 & $51.7 \%$ & $85.0 \%$ & $33.3 \%$ & $<.0001$ \\
\hline Overall average & $216 / 220$ & $48.9 \%$ & $\mathbf{7 7 . 7 \%}$ & $28.8 \%$ & $<.0001$ \\
\hline
\end{tabular}

a These are all seminars with pre- and posttests. Occasional seminars had no test questions supplied by the leader.

${ }^{\mathrm{b}}$ Variations in overall $\mathrm{n}$ size due to some seminars being offered in more years than others. If present (“ $p$ "), $\mathrm{n} / \mathrm{n}=\mathrm{pre} / \mathrm{post}$ sample sizes.

c Knowledge change represents the difference in the percentage of questions answered correctly by residents from pre-tests to posttests for each workshop.

${ }^{c}$ Pre- and post- are unmatched. Independent samples $t$-test for difference in pre- and posttest knowledge scores.

This study was limited by a small cohort size within a single residency program; findings may not be generalizable to other programs. Outcomes may have been influenced minimally by workshop adjustments after written and focus group feedback. The LUCC was implemented simultaneously with the beginning of the residency, and both have undergone continuous quality improvement. The positive change in resident cultural awareness and confidence on the annual surveys are likely from both the LUCC and practice in an FQHC. Changes in beliefs were not statistically significant and merit further investigation. However, preand post-LUCC surveys indicated significant knowledge gain attributable to individual sessions, and in focus groups, residents reiterated the value of immersion in issues such as homelessness, addiction, and refugee status in settings outside of FQHC practice. Although this curriculum was implemented in a family medicine residency with an urban underserved continuity practice, the experiential workshop format and the diversity of seminar topics are generalizable to other specialties and practice settings, with modification of content regarding local resources.

This study shows that a longitudinal underserved community curriculum can improve the knowledge, attitudes, and confidence of residents in an urban underserved residency. The next step is to implement and evaluate similar longitudinal curricula in diverse settings. 
Table 4: Residents' Self-Reports Before and After Participation in the LUCC ${ }^{\text {a }}$

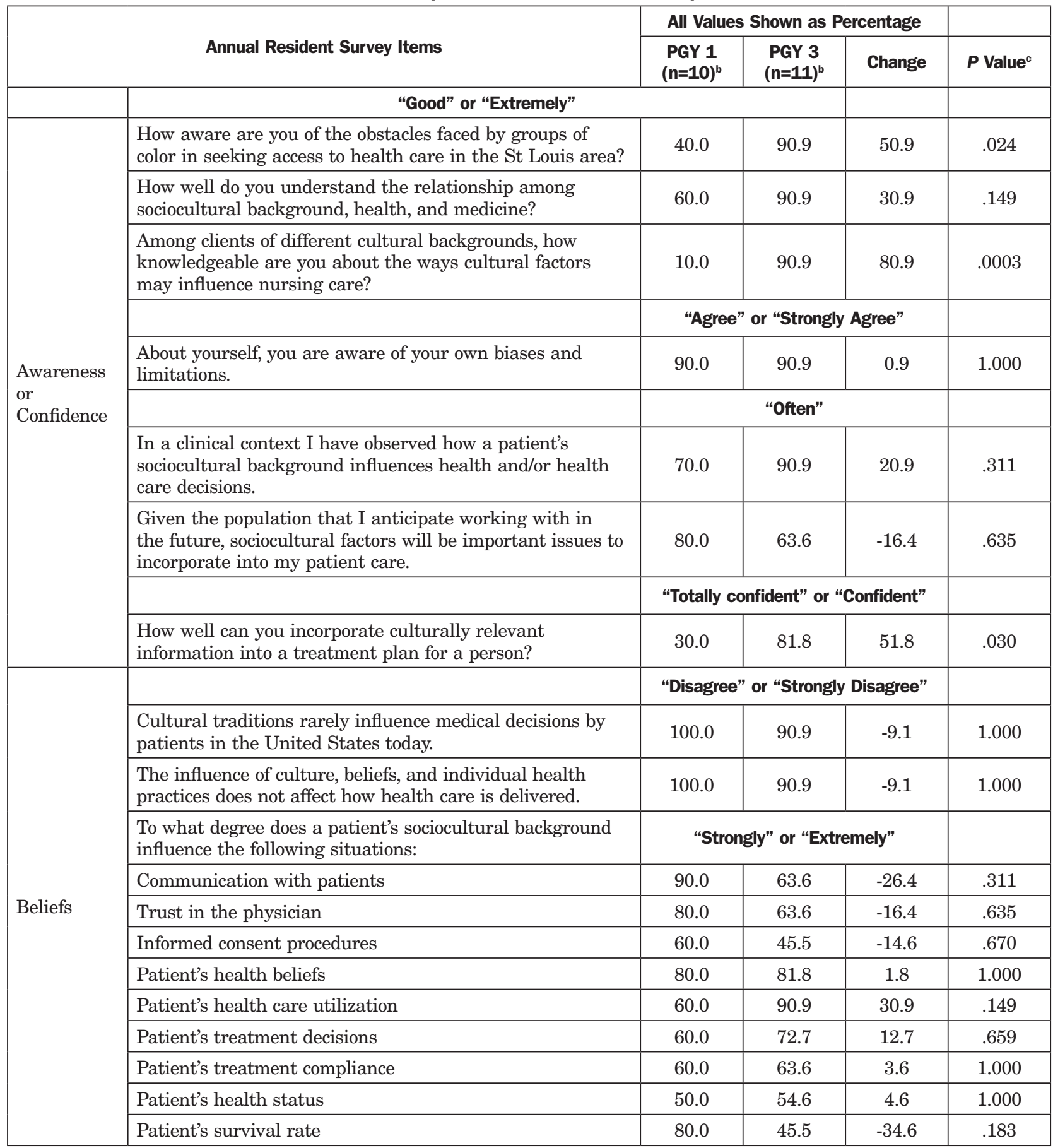

${ }^{a}$ Longitudinal underserved community curriculum.

${ }^{\mathrm{b}}$ Discrepancy in n size between PGY1 and PGY3 due to one resident in the class of 2015 missing the PGY-1 student survey.

c PGY1 and PGY3 are unmatched. Fisher exact test for difference in PGY1 to PGY3. 
Table 5: Written Feedbacka: Postworkshop, Program Year 2 Illustrating Themes of Greater Understanding of the Challenges and Barriers Faced by Underserved Patients and Increased Knowledge of Community Resources

\begin{tabular}{|c|c|}
\hline Workshop & In what ways do you think the [workshop] will affect the way you practice medicine? \\
\hline $\begin{array}{l}\text { Addiction and } \\
\text { Homelessness }\end{array}$ & $\begin{array}{l}\text { "Better understanding of afflictions prevalent in homeless and addicted populations. More } \\
\text { knowledge of community outreach and resources available." }\end{array}$ \\
\hline $\begin{array}{l}\text { Child Abuse and Family } \\
\text { Dynamics }\end{array}$ & $\begin{array}{l}\text { "I now will include abuse as a differential diagnosis more frequently and know what to do if } \\
\text { I find it." }\end{array}$ \\
\hline $\begin{array}{l}\text { Child Developmental and } \\
\text { Educational Issues }\end{array}$ & $\begin{array}{l}\text { "I'll be more understanding of what parents have to do to work with schools and try to be a } \\
\text { better advocate for them." } \\
\text { "Make me more empathetic to parents with concerns about child's behavior. I will better } \\
\text { know what to look for and advice to give for coping." }\end{array}$ \\
\hline Community Elder Support & $\begin{array}{l}\text { "I will be more effective at identifying dementia." } \\
\text { "Know of more resources for my senior/geriatric patients." }\end{array}$ \\
\hline $\begin{array}{l}\text { Disabilities and Implicit } \\
\text { Bias }\end{array}$ & $\begin{array}{l}\text { "It will help to not make assumptions. To ask open-ended questions. More information on } \\
\text { referral services." }\end{array}$ \\
\hline International Health & $\begin{array}{l}\text { "Better understanding of the struggles faced by refugees that we take for granted." } \\
\text { "Insight into Somali and Bosnian patients' prior experiences and culture." }\end{array}$ \\
\hline Medical Humanism & $\begin{array}{l}\text { "Remember the therapeutic value of touch and physical exam." } \\
\text { "I think it will help me focus on why I went into medicine and how to better counsel the } \\
\text { patients and answer their questions." } \\
\text { "The self-reflection at this point of residency enables us to find areas in which we can change } \\
\text { and still have time to change them." }\end{array}$ \\
\hline Neighborhood Safety Net & $\begin{array}{l}\text { "Help me to be more aware of the resources available and direct patients to places where } \\
\text { they can be assisted beyond my scope of practice." } \\
\text { "Better knowledge of community resources and situations our patients come from." }\end{array}$ \\
\hline $\begin{array}{l}\text { Pediatric Environment and } \\
\text { Nutrition in Underserved } \\
\text { Neighborhoods }\end{array}$ & $\begin{array}{l}\text { "I'll be more cognizant of the resources available to my patients and try to work within their } \\
\text { limitations. I will also make them more aware of available fitness activities." } \\
\text { "Better understanding of patient barriers to weight loss and healthy eating." }\end{array}$ \\
\hline State Health Policy & $\begin{array}{l}\text { "It will make me more likely to participate with advocacy" } \\
\text { "More knowledge of ways in which we as MDs may be able to positively effect change in } \\
\text { legislative policy." }\end{array}$ \\
\hline
\end{tabular}

aTable includes representative feedback provided on the posttests of each LUCC workshop in program year 2.

ACKNOWLEDGMENTS: Portions of this curriculum, but not the current analysis, have been presented at 37th Forum for Behavioral Science in Family Medicine, Chicago IL, September 23, 2016, STFM Annual Spring Conference, Minneapolis MN, May 2, 2016, and the STFM Annual Spring Conference, Orlando FL, April 26, 2015.

FUNDING: This project was supported by the Health Resources and Services Administration (HRSA) of the US Department of Health and Human Services (HHS) under grant number D58HP23229, Residency Training in Primary Care, total award amount: $\$ 652,421$. This information or content and conclusions are those of the authors and should not be construed as the official position or policy of, nor should any endorsements be inferred by HRSA, HHS, or the US Government.
CORRESPONDING AUTHOR: Address cor respondence to Christine Jacobs, MD, Department of Family and Community Medicine, Saint Louis University School of Medicine, 1402 South Grand Blvd, St Louis, MO 63140. 314-951-7230. Fax: 314-951-7234. christine.jacobs@health.slu.edu.

\section{References}

1. Betancourt JR, Green AR, Carrillo JE, Park ER. Cultural competence and health care disparities: key perspectives and trends. Health Aff (Millwood). 2005;24(2):499-505.

2. Betancourt JR. Cultural competence and medical education: many names, many perspectives, one goal. Acad Med. 2006;81(6):499-501.
3. Butler M, McCreedy E, Schwer N, et al. Improving Cultural Competence to Reduce Health Disparities [Internet]. Rockville (MD): Agency for Healthcare Research and Quality (US); 2016 Mar. (Comparative Effectiveness Reviews, No. 170.) https://www.ncbi.nlm.nih. gov/books/NBK361126/. Accessed October 26, 2018.

4. Chin MH, Clarke AR, Nocon RS, et al. A roadmap and best practices for organizations to reduce racial and ethnic disparities in health care. J Gen Intern Med. 2012;27(8):992-1000.

5. Smith-Campbell B. A health professional students' cultural competence and attitudes toward the poor: the influence of a clinical practicum supported by the National Health Service Corps. J Allied Health. 2005;34(1):5662. 
6. Aeder L, Altshuler L, Kachur E, et al. The "Culture OSCE"-introducing a formative assessment into a postgraduate program. Educ Health (Abingdon). 2007;20(1):11.

7. Schlotthauer AE, Badler A, Cook SC, Pérez DJ, Chin $\mathrm{MH}$. Evaluating interventions to reduce health care disparities: an RWJF program. Health Aff (Millwood). 2008;27(2):568-573.

8. Kachur EK, Altshuler L. Cultural competence is everyone's responsibility! Med Teach. 2004;26(2):101-105.

9. Godkin MA, Savageau JA. The effect of a global multiculturalism track on cultural competence of preclinical medical students. Fam Med. 2001;33(3):178-186.
10. Jeffreys MR. A transcultural core course in the clinical nurse specialist curriculum. Clin Nurse Spec. 2002;16(4):195-202.

11. Jeffreys MR, Smodlaka I. Construct validation of the Transcultural Self-Efficacy Tool. J Nurs Educ. 1999;38(5):222-227.

12. Godkin M, Savageau J. The effect of medical students' international experiences on attitudes toward serving underserved multicultural populations. Fam Med. 2003; 35:273-278.

13. Tang TS, Fantone JC, Bozynski MEA, Adams BS. Implementation and evaluation of an undergraduate sociocultural medicine program. Acad Med. 2002;77(6):578-585.
14. Hasnain M, Massengale L, Dykens A, Figueroa E. Health disparities training in residency programs in the United States. Fam Med. 2014;46(3):186-191.

15. Strelnick AH, Anderson MR, Braganza S, et al. Health disparities training in residency programs in the United States. Fam Med. 2014;46(10):809-810. 